\title{
Vitamin D Intoxication in An Elderly: A Case Report
}

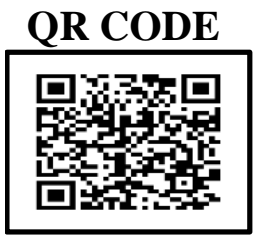

\section{SAHIL SINGH' ${ }^{*_{1}}$, PRERNIKA MITTAL ${ }^{2}$, AJAY SHARMA²}

Vitamin D is a very common prescribed drug for numerous indications. Due to scarce knowledge and poor awareness of the various formulations, preparations and dosages of Vitamin D, there are many chances of prescription errors, medication errors, product use issue and undesirable adverse drug reactions. We hereby detail case of 70-year-old ex-army gentleman reported to us with a history of lethargy, confusion, reduced appetite and gait imbalance since few days with a history of knee replacement surgery 2 years back. Medical history was not of much relevance before it was revealed that he was getting cholecalciferol injection with a strength of 600000 IU once a week for few months. He was detected to have very high serum vitamin D level and hypercalcemia. He was started on intravenous fluids, diuretics and glucocorticoids. In a few days, after effective treatment, the patient was discharged in a recovering stage and advised to stop intake calcium and vitamin D in any form. At his last follow up, after a few months of discharge, he had totally recovered.

KEYWORDS: Vitamin D, Hypervitaminosis D, Hypercalcemia

\section{INTRODUCTION}

Vitamin D is an important drug that plays a key role in maintenance of bones and calcium metabolism. The deficiency of Vitamin D deficiency not only leads to hypocalcemic state and bone mineralization defects but also is co-related with increased risks of extraskeletal complications including autoimmune disorders, chronic obstructive pulmonary disease, cancer, and metabolic syndrome. Those with low levels of Vitamin D are more likely to develop cardiovascular disorders ${ }^{1}$, insulin resistance ${ }^{2}$ and asthma ${ }^{3}$, but on the other hand unintentional, accidental, non-prescribed and non-recommended use of vitamin D may lead to potentially life threatening hazards. Both Vitamin D deficiency and insufficiency are considered to be public health issues globally. Tu-Tunji was the first one to report a case of vitamin D toxicity back in 1931. The case concerned a 2-year-old male infant with overdose of vitamin D supplement. ${ }^{4}$ We hereby present a case in which prescribed parentral intake of Vitamin D led to toxicity in an elderly patient.

\section{CASE REPORT}

A 7o-year-old ex-army gentleman reported to us with a history of nausea, vomiting, lethargy, confusion, reduced appetite, burning pain in the abdomen, body weakness and gait imbalance since a few days. Case history detailed no incidence of head injury, accident or fall. He was not taking any medication except metformin for diabetes since 8 years. The patient had undergone a knee replacement surgery 2 years ago.

General examination showed absence of pallor, cyanosis, clubbing, icterus, edema and lymphadenopathy. Blood pressure was normal and pulse was 99/min. Abdominal examination, chest auscultation and cardiovascular work up showed no kind of abnormality. Magnetic resonance imaging on admission was unremarkable except for some age related changes. Electrocardiogram, ultrasound abdomen, computed tomography chest were also normal. Screening for cerebral lesions and malignant lesions came out to be negative. Cerebrospinal fluid examination revealed normal results glucose and protein level. Central nervous system examination showed that there was generalized muscle weakness with planters affected.

On further investigation, he revealed and brought to our notice that during his follow up sessions after surgery, he was being injected with some Vitamin injection but could not recall the exact name. His orthopaedic surgeon was called up to know the details as the patient had lost the prescription. The concerned doctor that the patient was being given cholecalciferol injection with a strength of 600000 IU once a week for few months. The laboratory investigations revealed the following results: $\mathrm{Hb} 12.1 \mathrm{~g} / \mathrm{dl}$, Serum Calcium $15 \mathrm{mg} / \mathrm{dl}$, Serum 25 Hydroxy D $269.50 \mathrm{ng} / \mathrm{ml}$, urea 50 $\mathrm{mg} / \mathrm{dl}$, Serum Phosphorus 5.5mg/dl, creatinine 1.87 
$\mathrm{mg} / \mathrm{dl}$, blood urea $55 \mathrm{mg} / \mathrm{dl}$ and serum PTH of 0.20 $\mathrm{pg} / \mathrm{ml}$ and a magnesium level of magnesium level was $1.5 \mathrm{mg} / \mathrm{dl}$.

On the basis of the detailed history, clinical examination and laboratory examinations, a diagnosis of hypercalcemia following hypervitaminosis D was established, and he was admitted and started on hydration with intravenous fluids, oral diuretics, bisphosphonates and glucocorticoids. The patient was feeling better after being admitted. The hypercalcemic state started to resolve, the patient showed a clinical improvement and eventually and his serum calcium came down to normal limits in 12 days and was discharged and advised not to take any food or supplement containing calcium or vitamin D. At the time of discharge, vitamin level was $221.44 \mathrm{ng} / \mathrm{ml}$. At his last follow up, four months after the discharge, the patient has returned to a normal state with resolved levels of Vitamin D.

\section{DISCUSSION}

This case study reports an ideal case of hypercalcemic complication followed by the event of hypervitaminosis D. This case also shows how important it is to get into the details of medical history and other factors while formulating a perfect diagnosis. Clear history of high dose Vit D injections with all the laboratory parameters favouring the diagnosis were of great help in initiation of early treatment. The cumulative dose of vitamin D in our patient was too high to obviously result in hypercalcemia. Vitamin D is one of the fat soluble vitamins and reported to be the most common in causing hypervitaminosis. This condition may result due to high intake of fat soluble vitamins through natural or fortified foods or taking of pharmaceutical preparation in excess as in this reported case. Both synthetic and natural forms are accountable for toxicity. Being fat soluble, it gets deposited in body fat, and it may take a time to reverse the toxicity.

Headache, nausea, vomiting, constipation, anorexia, hypertension, hypercalcemia, hypercalciuria, renal stones, hyperphosphatemia, polyuria, polydipsia and ectopic calcification of soft tissues are the common symptoms of vitamin D toxicity. ${ }^{5}$

Diagnosis of vitamin D toxicity is established by confirmatory biochemical evaluation and is characterized by high serum calcium, and high serum vitamin D levels. Treatment modalities include abstinence from all sources of calcium and vitamin D, avoidance of exposure to sunlight and other ultraviolet light sources, appropriate attention to hydration, volume repletion, use of loop diuretics, glucocorticoid therapy and bisphosphonate therapy. ${ }^{6-9}$

\section{CONCLUSION}

In cases of hypercalcemia, Vitamin D toxicity should always be considered as a differential diagnosis. In recent times, awareness regarding consequences of vitamin $\mathrm{D}$ deficiency has increased leading to an escalation in intake of vitamin $\mathrm{D}_{3}$ supplements lead to toxicity and complications like hypercalcemia. As it is said that excess of everything is bad, there is a need to formulate safety parameters for high dose vitamin $\mathrm{D}_{3}$ supplementation and educate people regarding the after effects of vitamin D toxicity. Healthcare professionals should make sure to prescribe the appropriate dose of vitamin $D$ to the deficient subjects. Such patients should be treated carefully and inadvertent use of vitamin $\mathrm{D}$ should be avoided.

\section{REFERENCES}

1. Wang TJ, Pencina MJ, Booth SL, Jacques PF, Ingelsson E, Lanier K, Benjamin EJ, D’Agostino RB, Wolf M, Vasan RS. Vitamin D deficiency and risk of cardiovascular disease. Circulation. 2008;29:117:50311.

2. von Hurst PR, Stonehouse W, Coad J. Vitamin D supplementation reduces insulin resistance in South Asian women living in New Zealand who are insulin resistant and vitamin D deficient-a randomised, placebo-controlled trial. British Journal of Nutrition. 2010;103:549-55.

3. Camargo Jr CA, Rifas-Shiman SL, Litonjua AA, RichEdwards JW, Weiss ST, Gold DR, Kleinman K, Gillman MW. Maternal intake of vitamin D during pregnancy and risk of recurrent wheeze in children at $3 \mathrm{y}$ of age-. The American journal of clinical nutrition. 2007;85:788-95

4. Tu-Tunji D. The toxicity of Vitamin D. The Lancet. 1931;217:53.

5. Bonillon R. Vitamin D: From photosynthesis, metabolism, and action to clinical application. Endocrinology. 6th ed.; 2010. p. 1089-110

6. Gupta AK, Jamwal V, Sakul, Malhotra P: Hypervitaminosis D and systemic manifestations: a comprehensive review. JIMSA Oct-Dec 2014; 27(4): 236-237.

7. Agraharkar M, Dellinger OD, Gangakhedkar AK et al. (eds.): Hypercalcemia. Medscape References, New York, USA 2012. 
8. Potts JT Jr, Juppner H: Disorders of the parathyroid gland and calcium homeostasis. [In:] Longo DL, Fauci AS, Kasper D et al. (eds.): Harrison's principles of Internal Medicine. Vol. 2, $18^{\text {th }}$ ed. McGraw Hill, New York 2012.
9. Selby P, Davies M, Marks JS, Mawer EB: Vitamin D intoxication causes hypercalcemia by increased bone resorption which responds to pamidronate. Clin Endocrinol (Oxf) 1995 Nov; 43(5):531-6.

Source of support: Nil, Conflict of interest: None declared

Cite this article as:

Singh S, Mittal S, Sharma A. Vitamin D Intoxication in An Elderly: A Case Report. Int Healthc Res J. 2019;3(4):147-149. https://doi.org/10.26440/IHRJ/0304.07257

AUTHOR AFFILIATIONS:

1. MBBS, MD, Private Practitioner, Panchkula, Haryana, India

2. MBBS, Private Practitioner, Karnal, Haryana, India

\section{CORRESPONDING ADDRESS}

Dr. Sahil Singh

Second Floor,

H. No 655 ,

Sector 25, Panchkula, India

sahil.singh.mdss[at]gmail[dot]com 